\title{
Variability Across the ARM SGP Area by Temporal and Spatial Scale
}

\author{
C. N. Long and T. P. Ackerman \\ Pacific Northwest National Laboratory \\ J. E. Christy \\ Columbia University \\ New York, New York
}

\section{Introduction}

The Surface Cloud Grid (SfcCldGrid) value-added product (VAP) uses the output of the Shortwave Flux Analysis VAP (Long and Ackerman 2000, Long et al. 1999, Long 2001) at 15-minute resolution for each of the 21 surface radiometer sites of the Atmospheric Radiation Measurement (ARM) Southern Great Plains (SGP) network area as input. The SfcCldGrid VAP uses the Analytic Approximation interpolation technique of Caracena (1987) to produce a $0.25^{\circ} \times 0.25^{\circ}$ grid across the ARM SGP area at 15-minute resolution. (More information about the SfcCldGrid VAP, and an analysis of the interpolation uncertainties associated with the gridded output, is presented in the ARM STM 2002 poster "Interpolation Uncertainties Across the ARM SGP Area," and the corresponding extended abstract, by Christy and Long.) The Figure 1 shows the location of the SGP surface sites by latitude/longitude, and the associated area (red box) of the SfcCldGrid VAP domain. By far, most analyses and comparisons to date have used SGP Central Facility (CF) data. The gridded output of the SfcCldGrid VAP allows us to ask the question: "How well does the SGP CF represent the broader area on various time and spatial scales?" To help address this question, we analyze the SGP grid from the grid point associated with the CF compared to grid "boxes" of increasing size centered on the CF grid point, as illustrated in Figure 2.

\section{Analysis by Grid Box Size}

For the ARM 1997 Cloud intensive operational period (IOP) (the Cloud Parameterization and Modeling Working Group "Case 3"), Figure 3 shows the daily average CF value of cloud amounts (top panel), and the corresponding average absolute difference from this CF value by area size (bottom panel). Note that on some days, the CF value does reasonably represent some larger area as evidenced by the small average absolute differences. However, on daily time scales, more often the CF does not well represent general circulation model (GCM) grid box scales. Thus, on these days, comparing a GCM model output to the CF data will not necessarily represent a "good" comparison. Figure 4 shows the same comparison of average sky cover and the same result, but for the 2000 Cloud IOP. Figure 5 is the measured over clear-sky SW ratio corresponding to the 2000 Cloud IOP data in the top right panel. Note the negative 


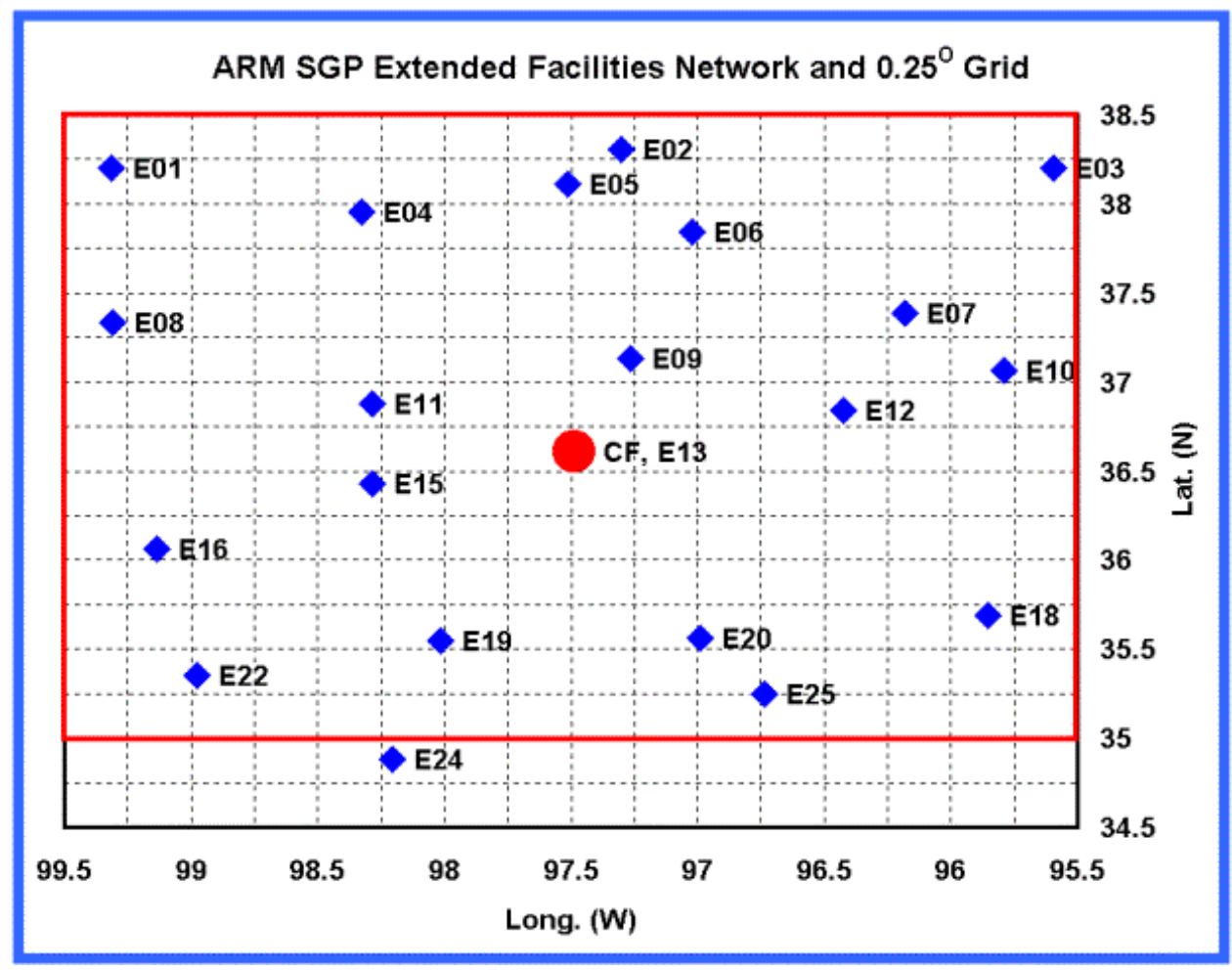

Figure 1. SGP surface sites by lat/long.

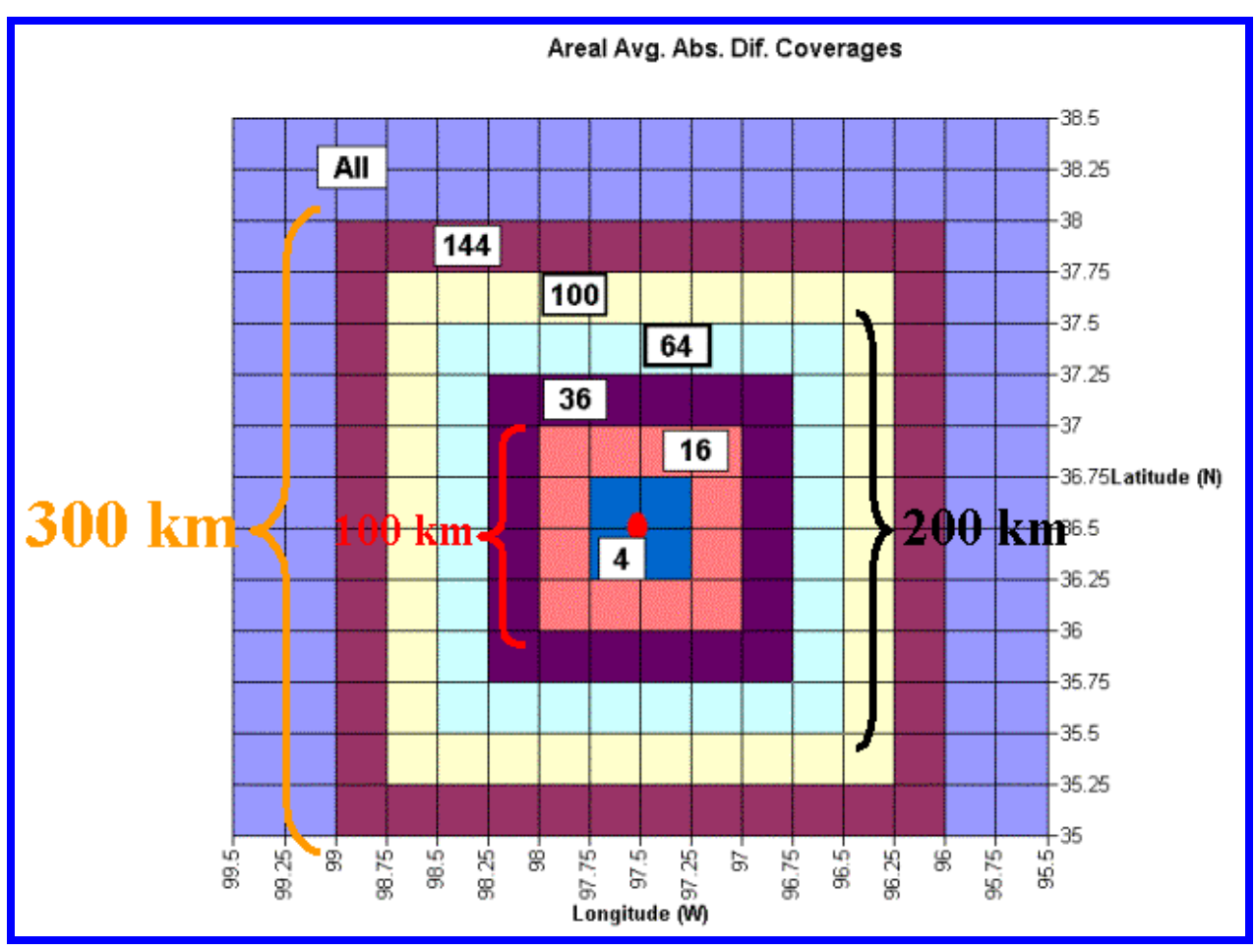

Figure 2. Illustration of analysis grid box sizes. 


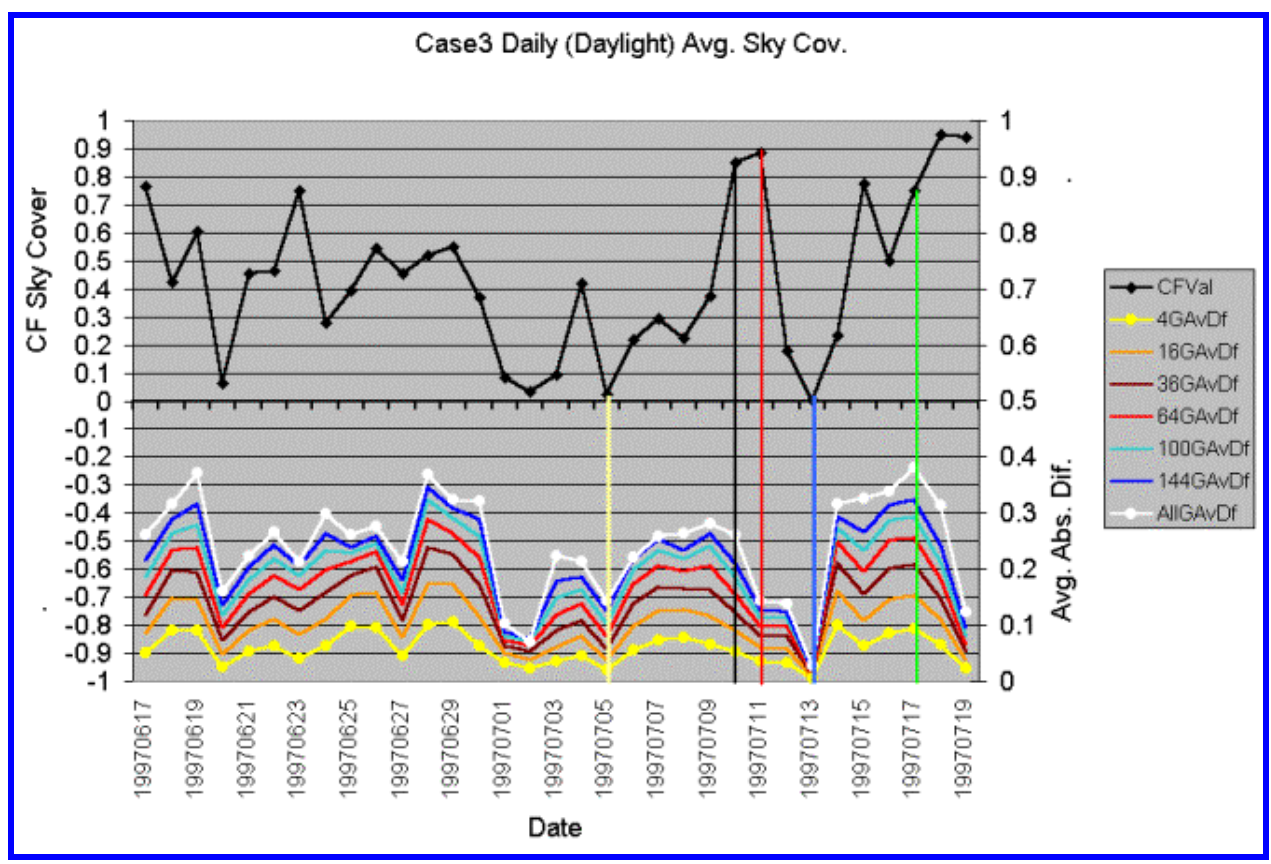

Figure 3. 1997 IOP sky cover for CF and SGP area.

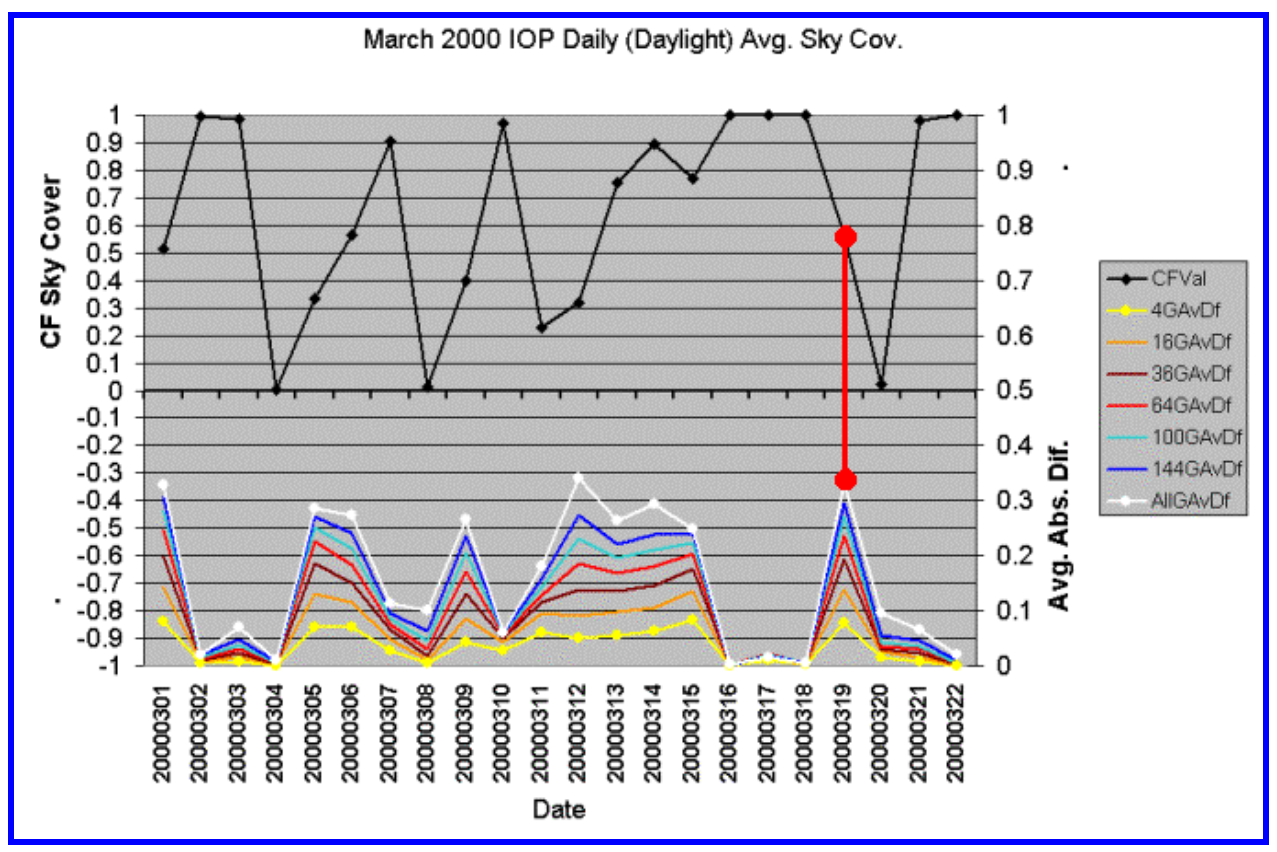

Figure 4. Same as Figure 3, but for 2000 IOP. 


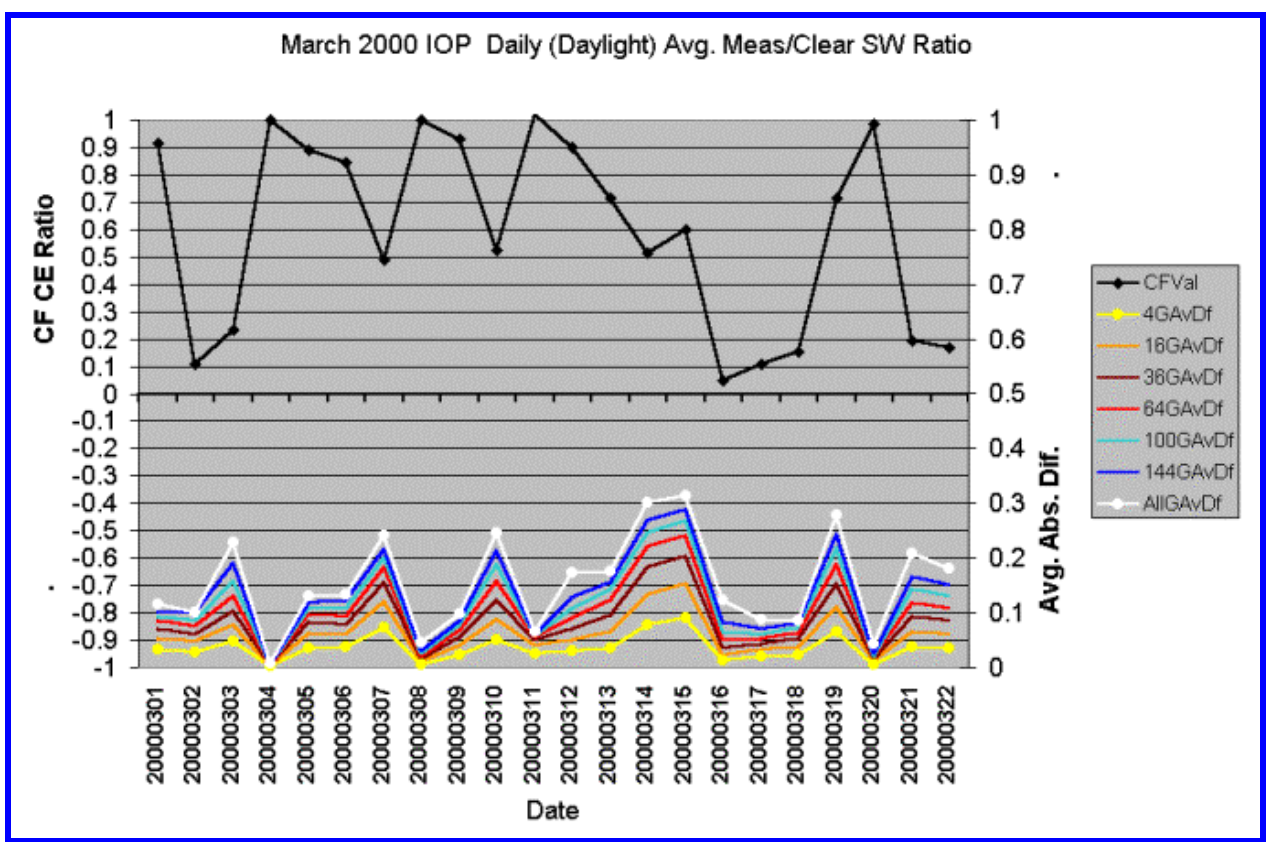

Figure 5. 2000 IOP cloud effect for CF and SGP.

correlation between the sky cover in the top panel and the shortwave (SW) "cloud effect" in the lower panel. However, the average absolute differences exhibit positively correlated behavior. Finally, Figure 6 shows the measured/clear-sky SW ratio for the 2000 Cloud IOP, but here for hourly instead of daylight averages. As expected, the decrease in temporal resolution tends to increase the average absolute differences.

\section{Frequency Distributions by Spatial Scales}

Figure 7 shows the frequency histogram of sky cover by area size for the 2000 Cloud IOP. Note that the occurrence of extreme values decreases as the area size increases. To understand this, imagine the frequency distribution of cloud cover for an area the size of the continental United States. The number of times that the entire country is cloud free, or completely overcast, would be infinitesimal if ever. Thus, care must be taken in statistical model/CF comparisons. The statistics for an area the size of a GCM grid box are not necessarily those expected for a surface point measurement. In addition, the frequency histogram of average absolute difference from the CF value of sky cover (Figure 8) shows that as the area size increases the representativeness of the CF measurements decreases, as evidenced by the increase of occurrence of larger differences as the area increases.

\section{Grid Plots and Analyses}

Figure 9 shows the average sky cover across the SGP area for the entire 2000 Cloud IOP period. During the three weeks of the IOP, the CF happened to experience more cloud cover than most of the SGP area, especially the south-southeast portion of the area. Figure 10 shows the 2000 Cloud IOP SW measured/ 


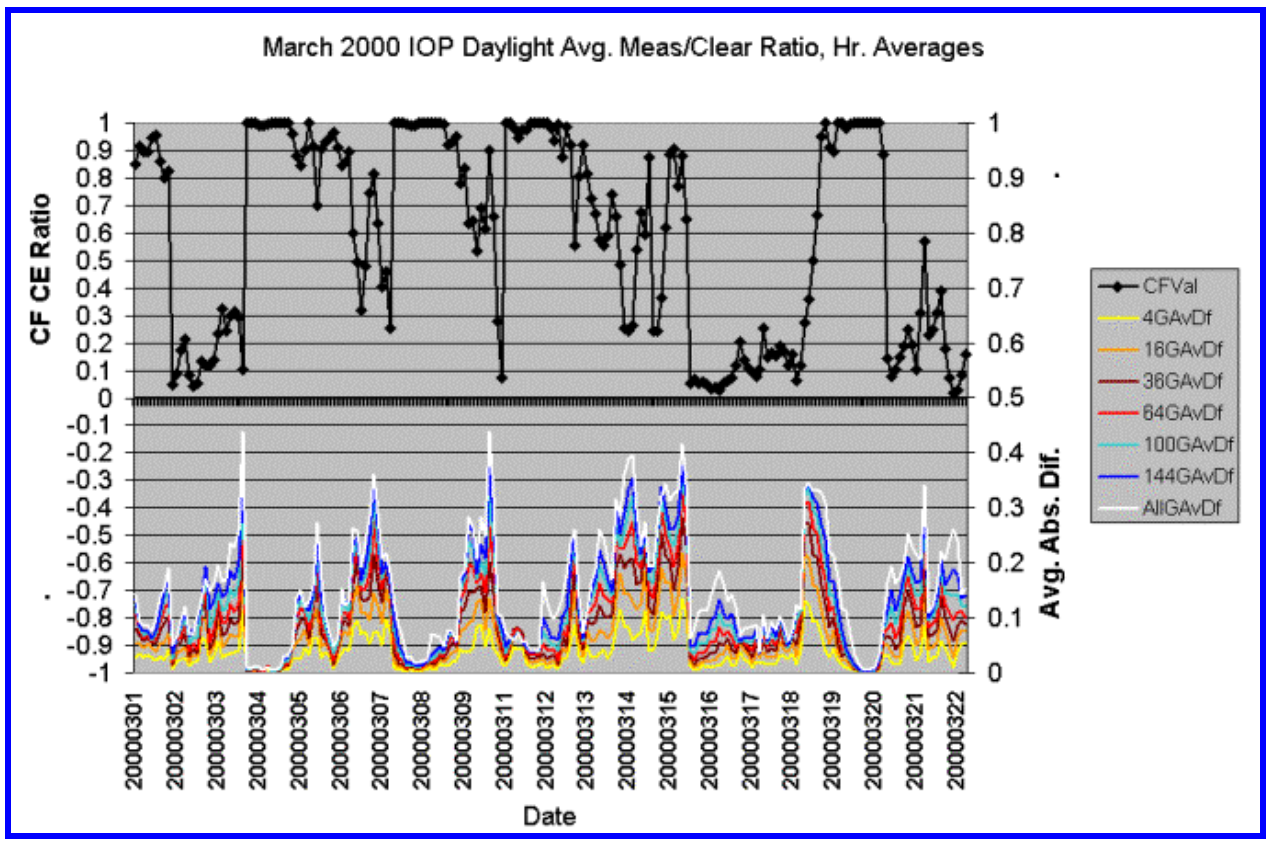

Figure 6. Same as Figure 3, but for hourly averages.

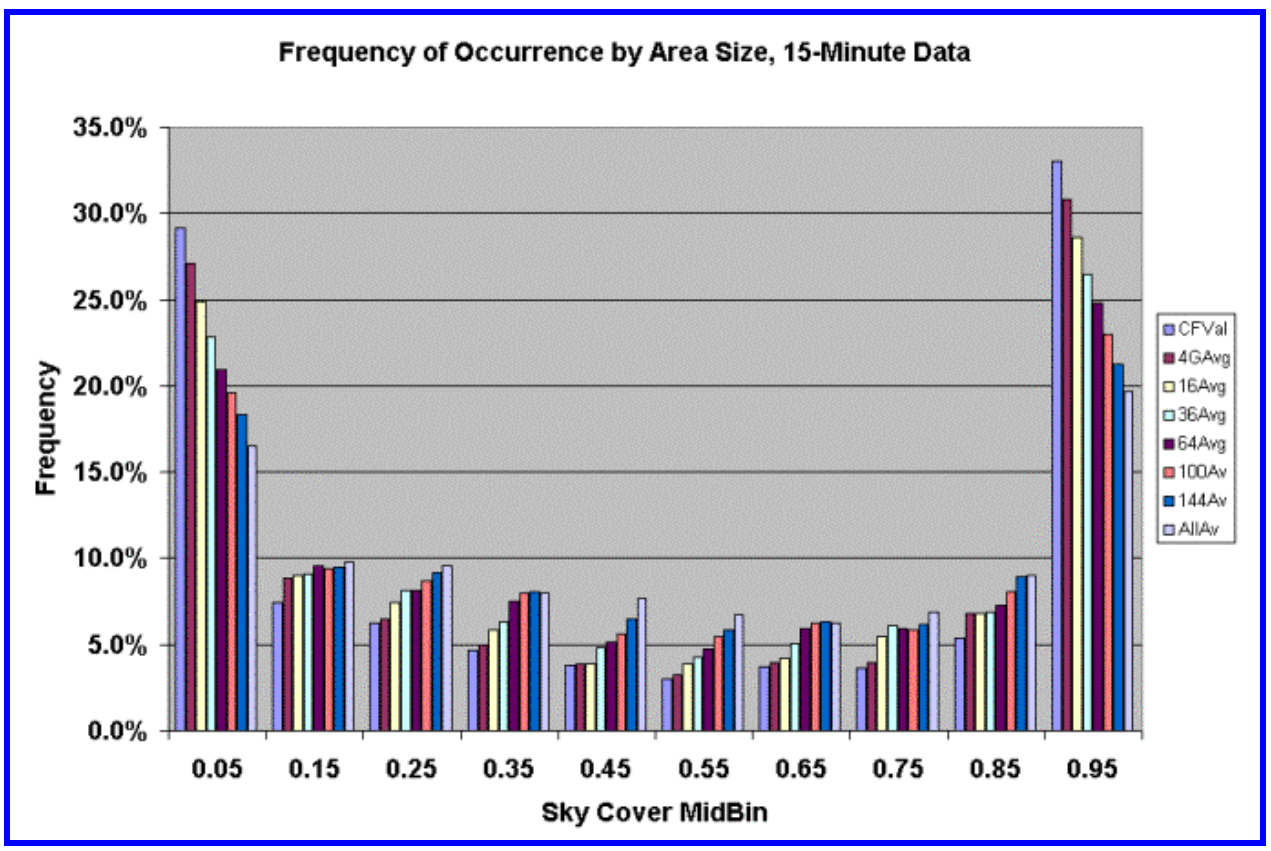

Figure 7. 2000 IOP sky cover frequency by area size. 
Twelfth ARM Science Team Meeting Proceedings, St. Petersburg, Florida, April 8-12, 2002

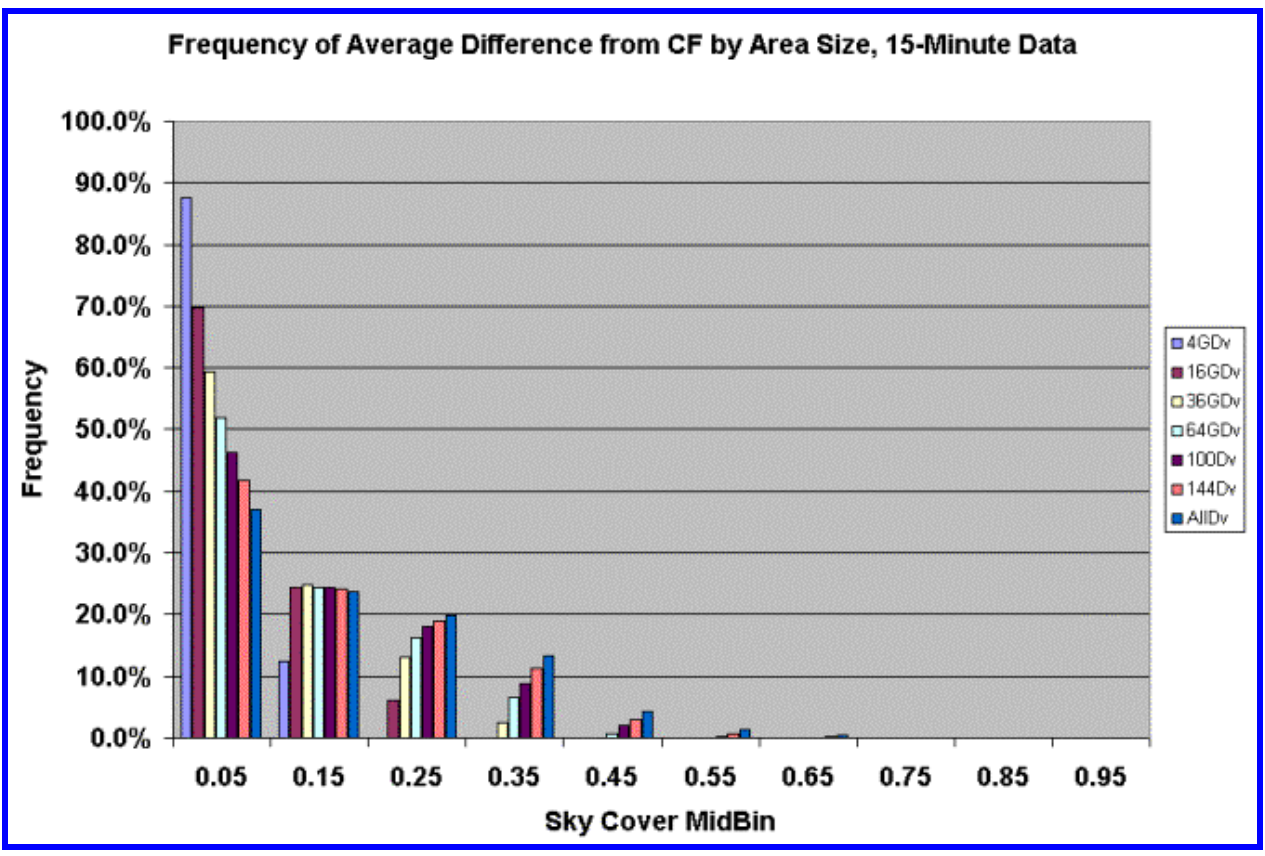

Figure 8. 2000 IOP frequency of avg. abs. difference.

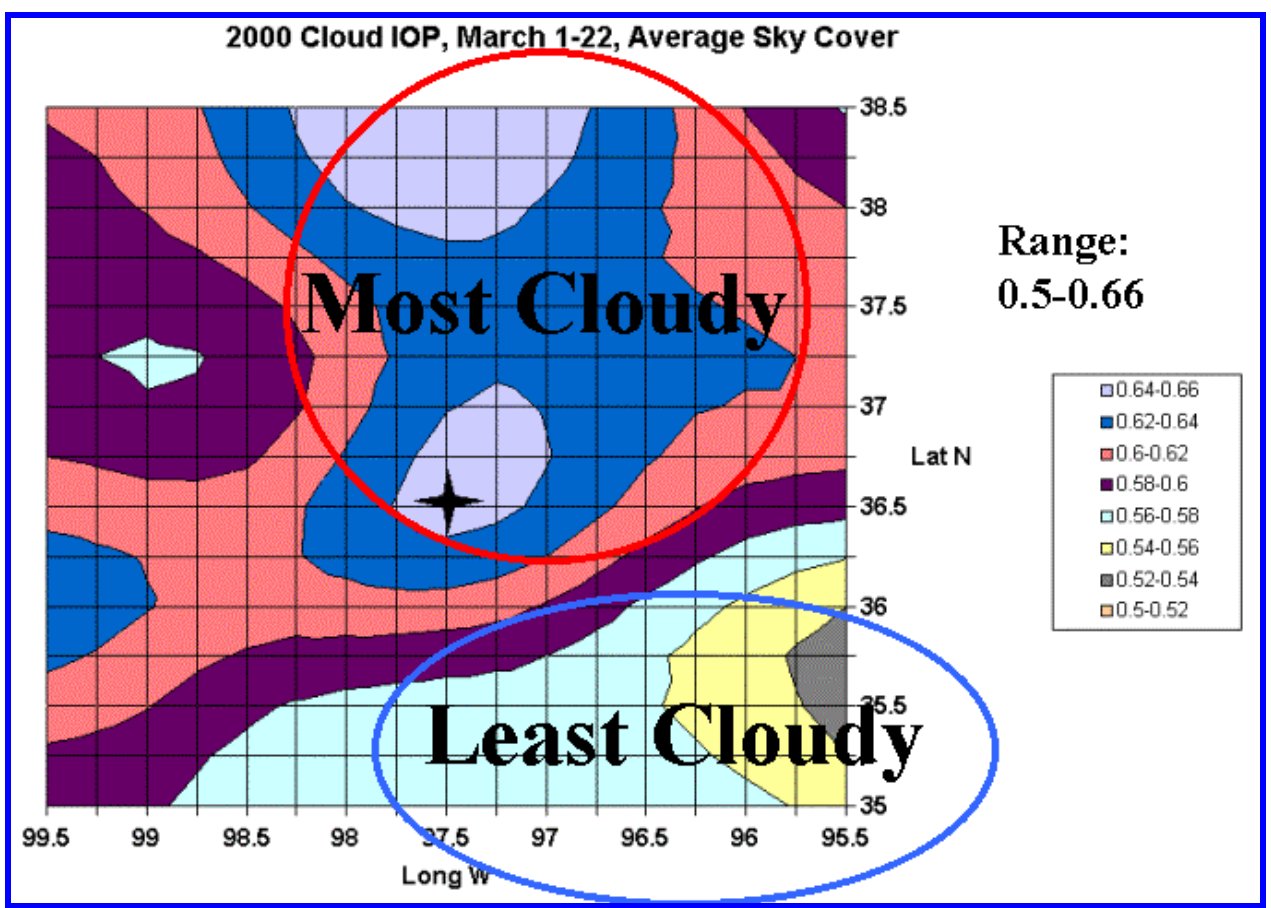

Figure 9. 2000 IOP sky cover for SGP area. 


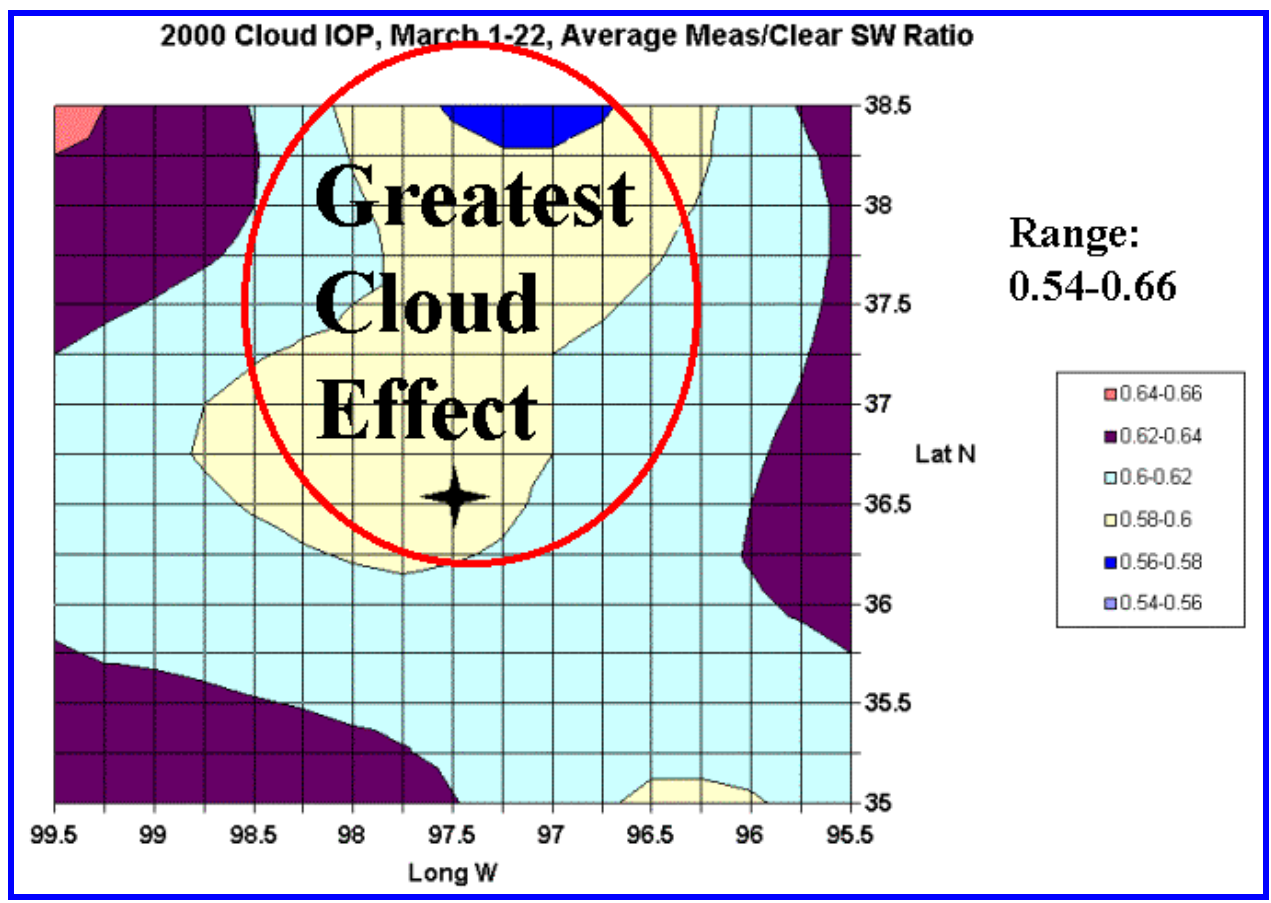

Figure 10. Same as Figure 9, but for cloud effect.

clear-sky (Cloud Effect) ratio. Naturally, where more cloudiness occurred, a greater cloud effect occurred. Thus, for the 2000 Cloud IOP, the CF measurements exhibit more cloud effect than most of the SGP area. Figures 11 and 12 are for the one month of the 1997 "Case 3" IOP. Note the larger range of sky cover values (0.25-0.6) compared to the 2000 IOP (0.5-0.66). The 1997 IOP exhibited less cloudiness in general than the $2000 \mathrm{IOP}$. In this case, the CF value is roughly representative of the mean, but this IOP had larger variability across the area than the 2000 IOP. And in the 1997 IOP case, the greatest cloud effect occurred in the northeast portion of the area.

\section{Spatial Correlation Analyses}

Figures 13 and 14 show the correlation to the CF value for the 2000 Cloud IOP (Figure 13) and the 1997 IOP (Figure 14). As expected, the correlation to the CF value decreases with distance. Thus, a statistical comparison using only CF data to represent the IOP is representative of only so much of the larger area. And while the 2000 IOP mean of the CF was more representative of the north central portion of the area (Figure 9), apparently the temporal evolution of the sky cover was not. The greater east-west correlation with distance, compared to north-south, is evidence of the generally west-east movement of weather systems across the area. In the 1997 IOP case (Figure 14), given the greater range of sky cover experienced during this IOP, the larger area is less correlated with the CF data. Again, however, there is a greater east-west correlation than north-south. 


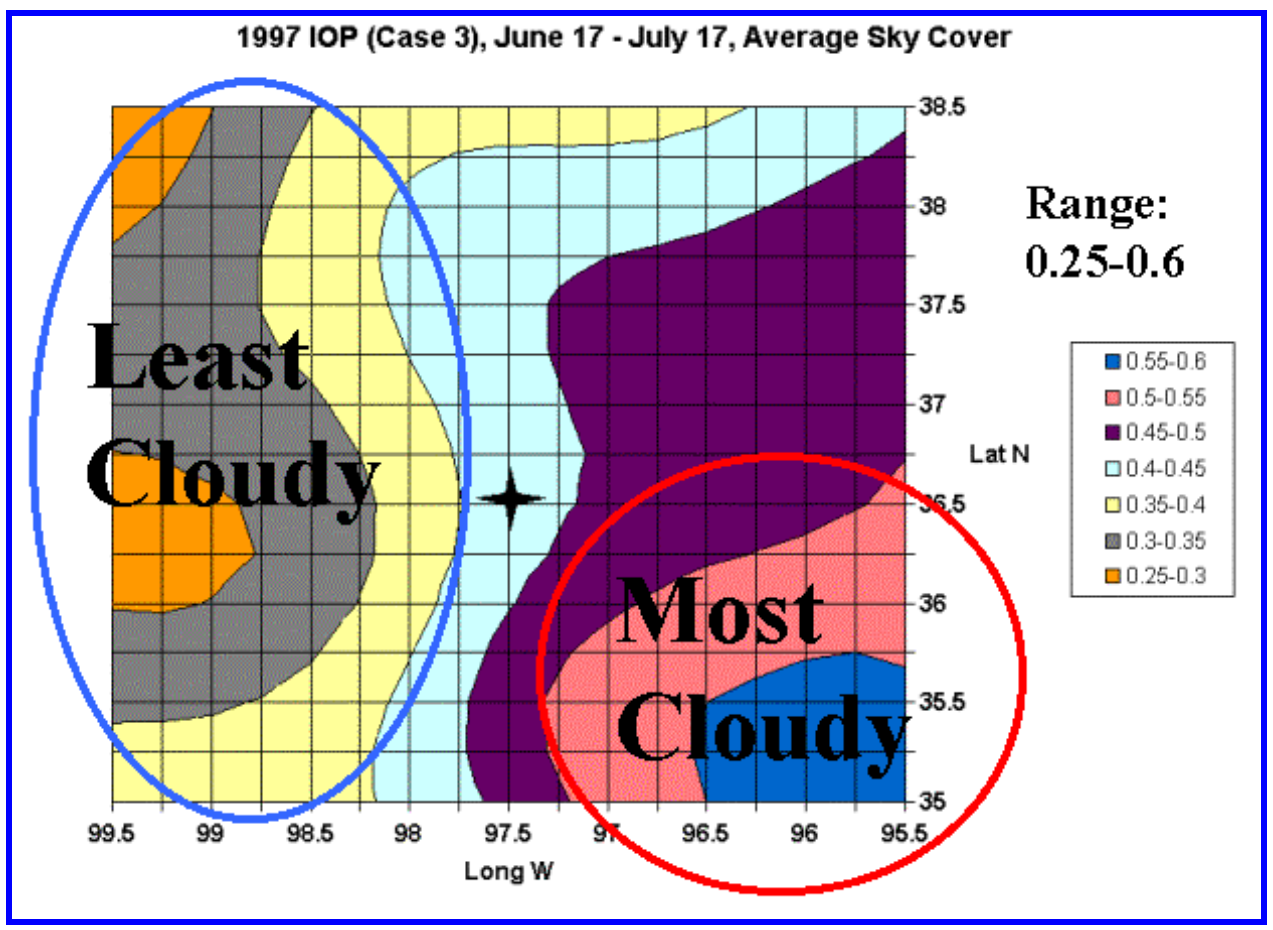

Figure 11. 1997 IOP sky cover for SGP area.

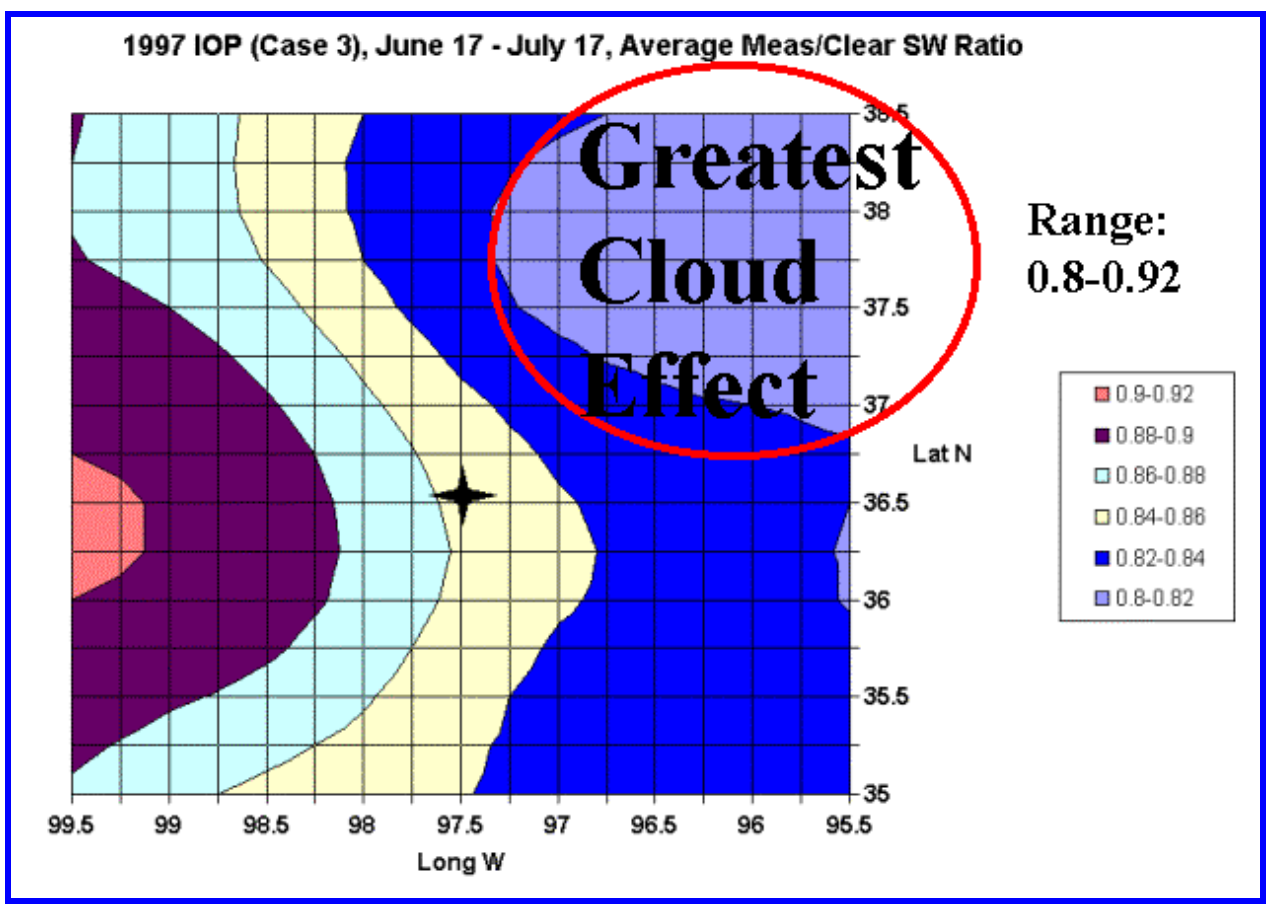

Figure 12. Same as Figure 11, but for cloud effect. 


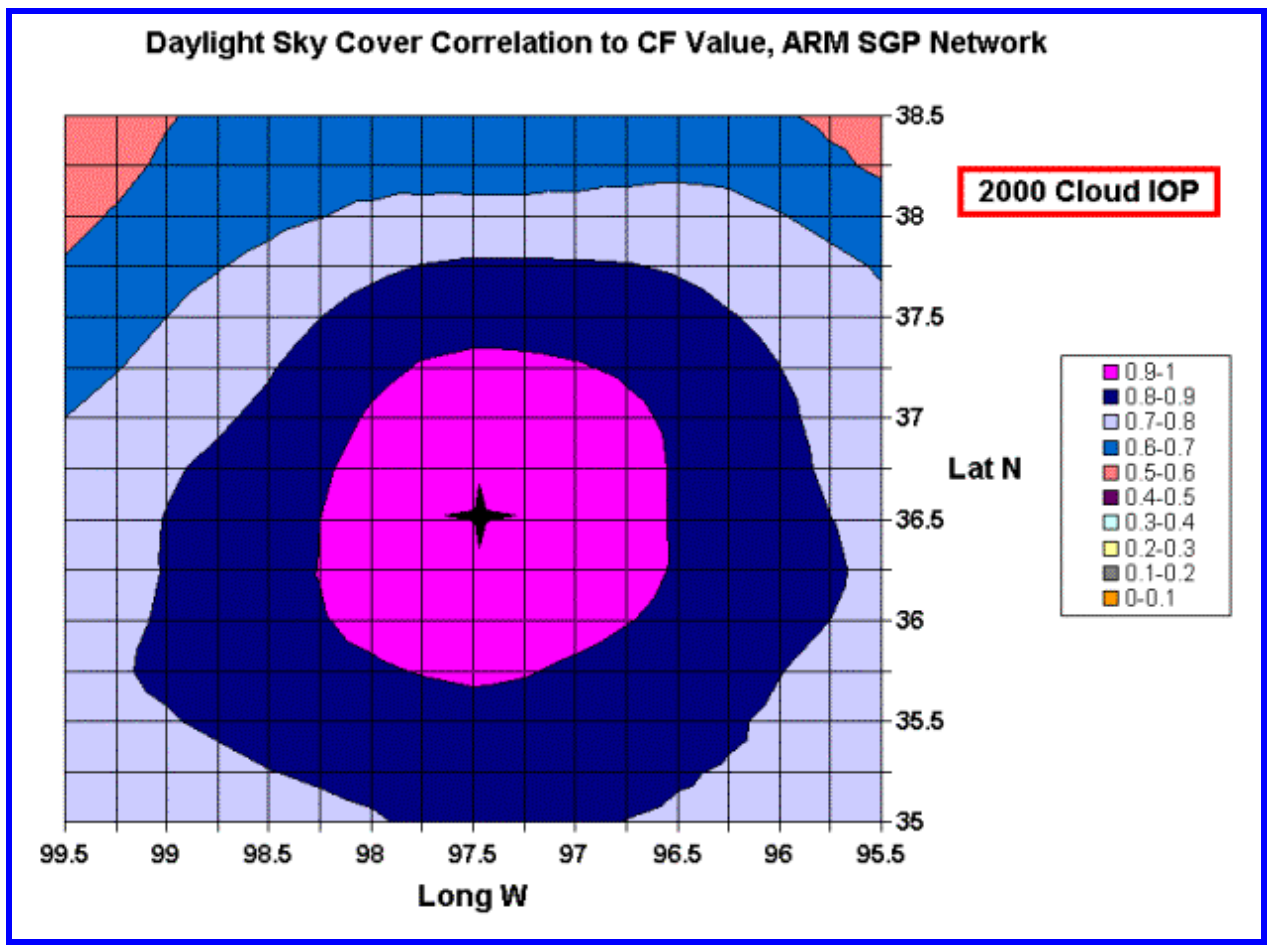

Figure 13. 2000 IOP sky cover correlation.

1997 IOP (Case 3), June 17 - July 17, Sky Cover Correlation to CF Value

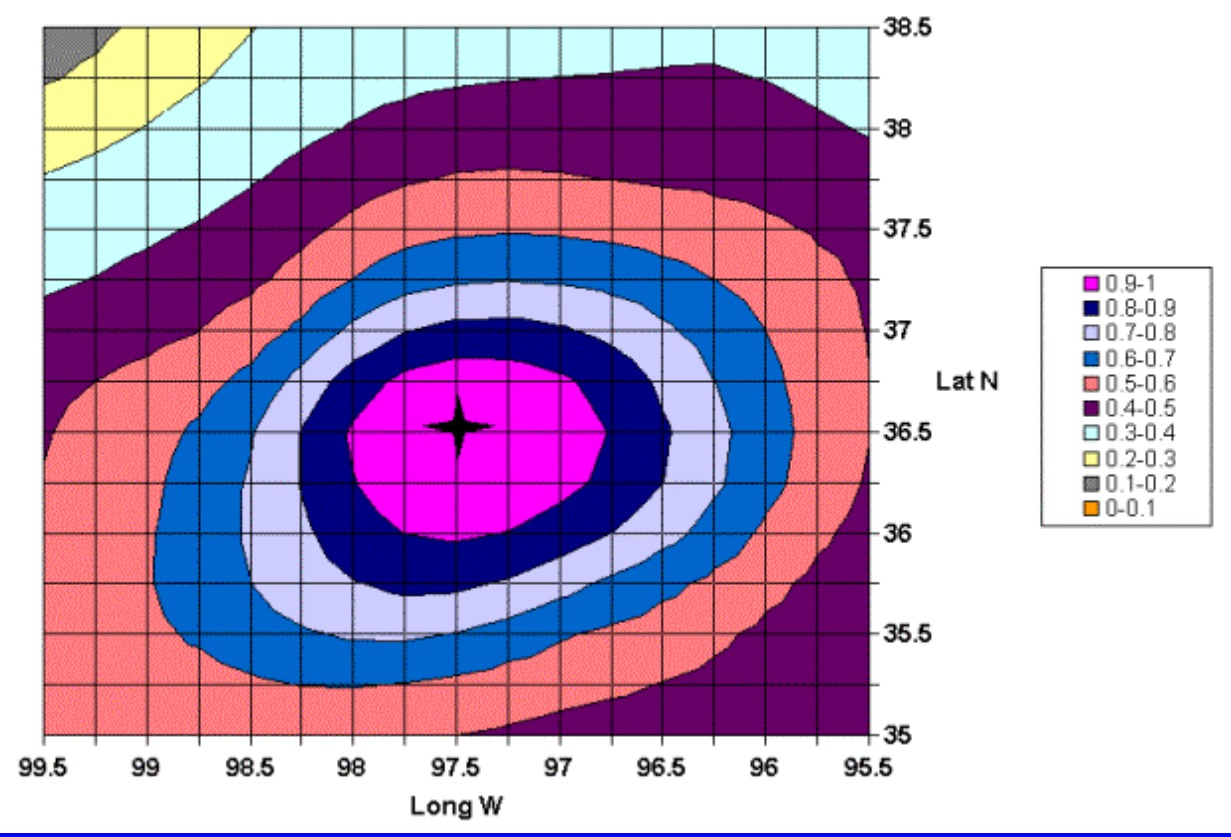

Figure 14. Same as Figure 13, but for 1997 IOP. 
Figures 15 and 16 show the correlation of each grid point from the correlation plots (Figures 13 and 14) versus the distance between the grid point and the CF grid point. The blue line is the average distance of the points in that correlation bin range. For the 2000 IOP three-week period (Figure 15), a study using $\mathrm{CF}$ data and requiring a degree of correlation of 0.8 or better would only represent an area within about a $125-\mathrm{km}$ radius of the CF. For the 1997 IOP (Figure 16), a study using CF data and requiring a degree of correlation of 0.8 or better would only represent an area within about a $75-\mathrm{km}$ radius of the $\mathrm{CF}$, or about half that of the 2000 IOP. The correlation and distance for given correlation decreases dramatically for individual days, shown in the Figures 17 and 18 for June 29, 1997. Note that the scale for Figure 18 is now from -1.0 to 1.0 .

\section{Correlation with Distance and Temporal Scale}

From the type of analysis shown in Figures 15, 16, and 18, the Figures 19-21 show the average distance in kilometers for the correlation bin ranging from $0.5-0.6$ (Figure 19) and 0.8-0.9 (Figure 20) for daily values from the years 2000 and 2001. In these Figures, the daily values are generated from 15-minute data, and the middle line (red Figure 19, blue Figure 20) represents a 21-day running mean through the data. On a daily basis the average distance for $0.5-0.6$ correlation (Figure 19) is about $125-150 \mathrm{~km}$. For a correlation of $0.8-0.9$ (Figure 20), the average distance is only $75-100 \mathrm{~km}$. But both plots exhibit significant variability from day to day from these average values. Thus, daily statistics generated from CF data can only be considered to represent a limited area, depending on the correlation needed for the particular study.

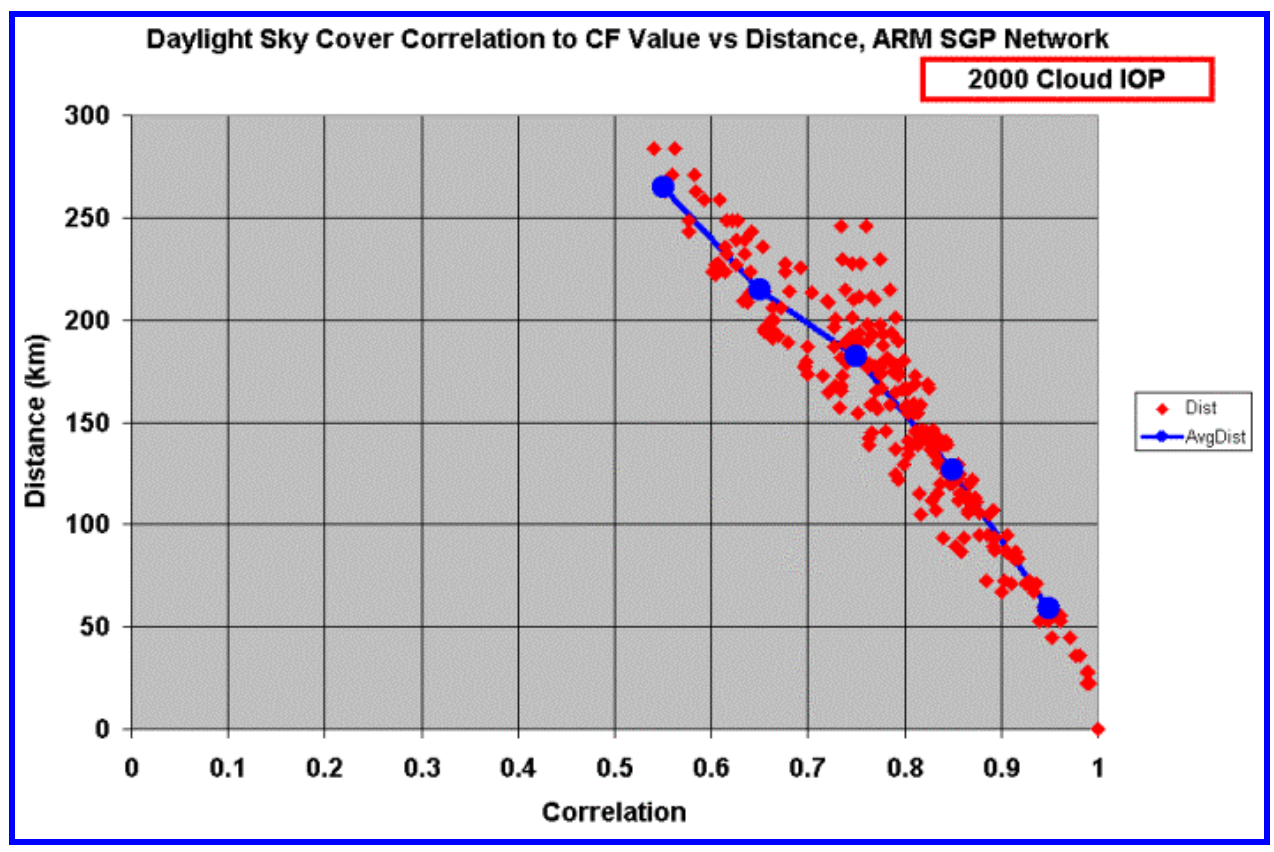

Figure 15. 2000 IOP correlation vs. distance. 
Twelfth ARM Science Team Meeting Proceedings, St. Petersburg, Florida, April 8-12, 2002

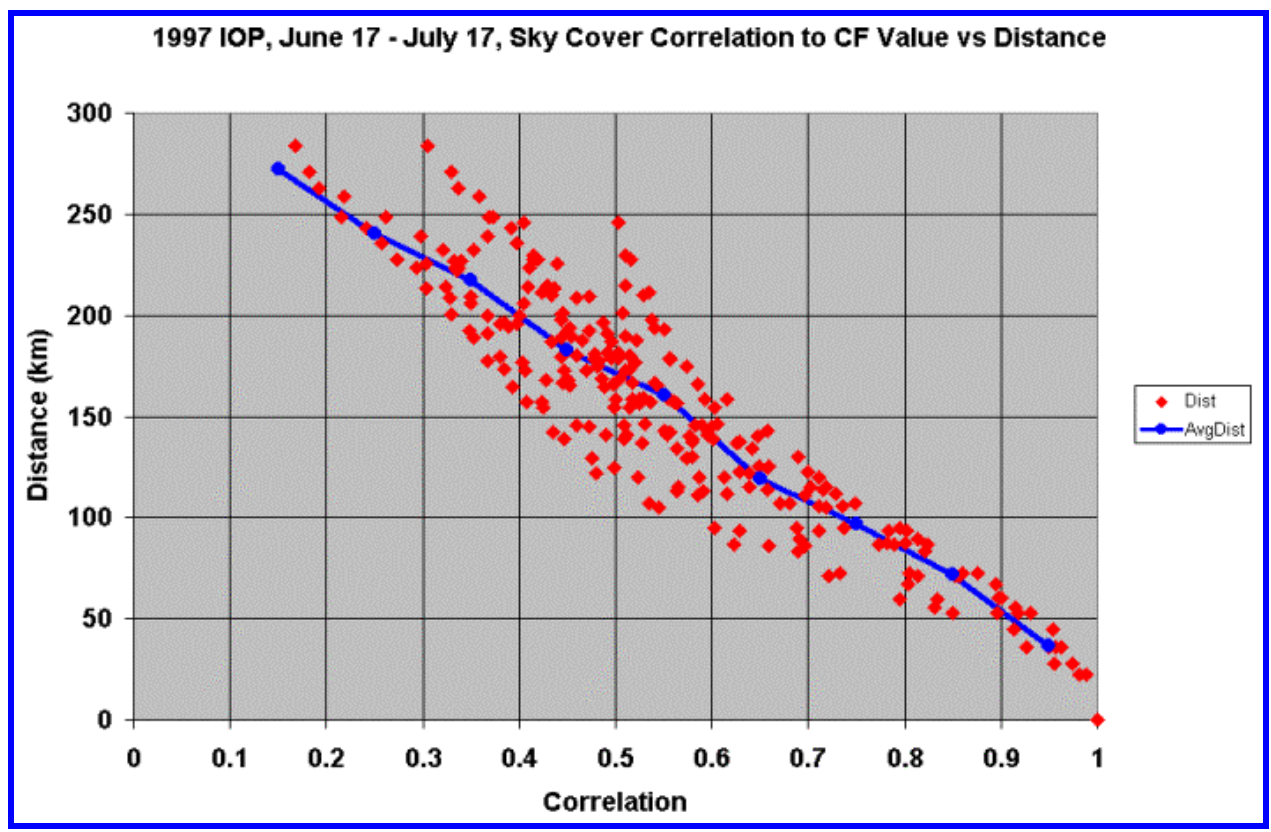

Figure 16. Same as Figure 15, abut for 1997 IOP.

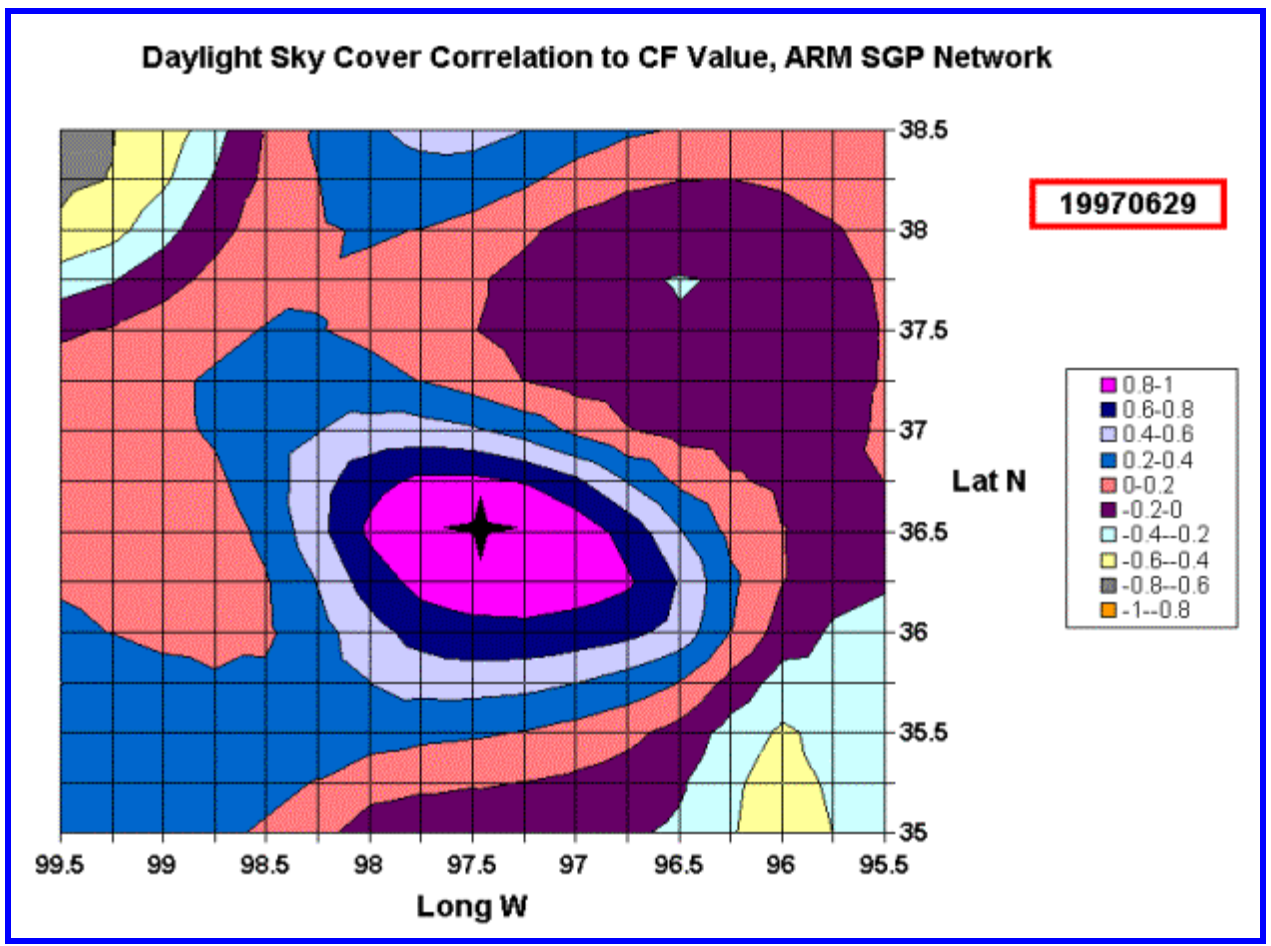

Figure 17. 19970629 sky cover correlation. 
Twelfth ARM Science Team Meeting Proceedings, St. Petersburg, Florida, April 8-12, 2002

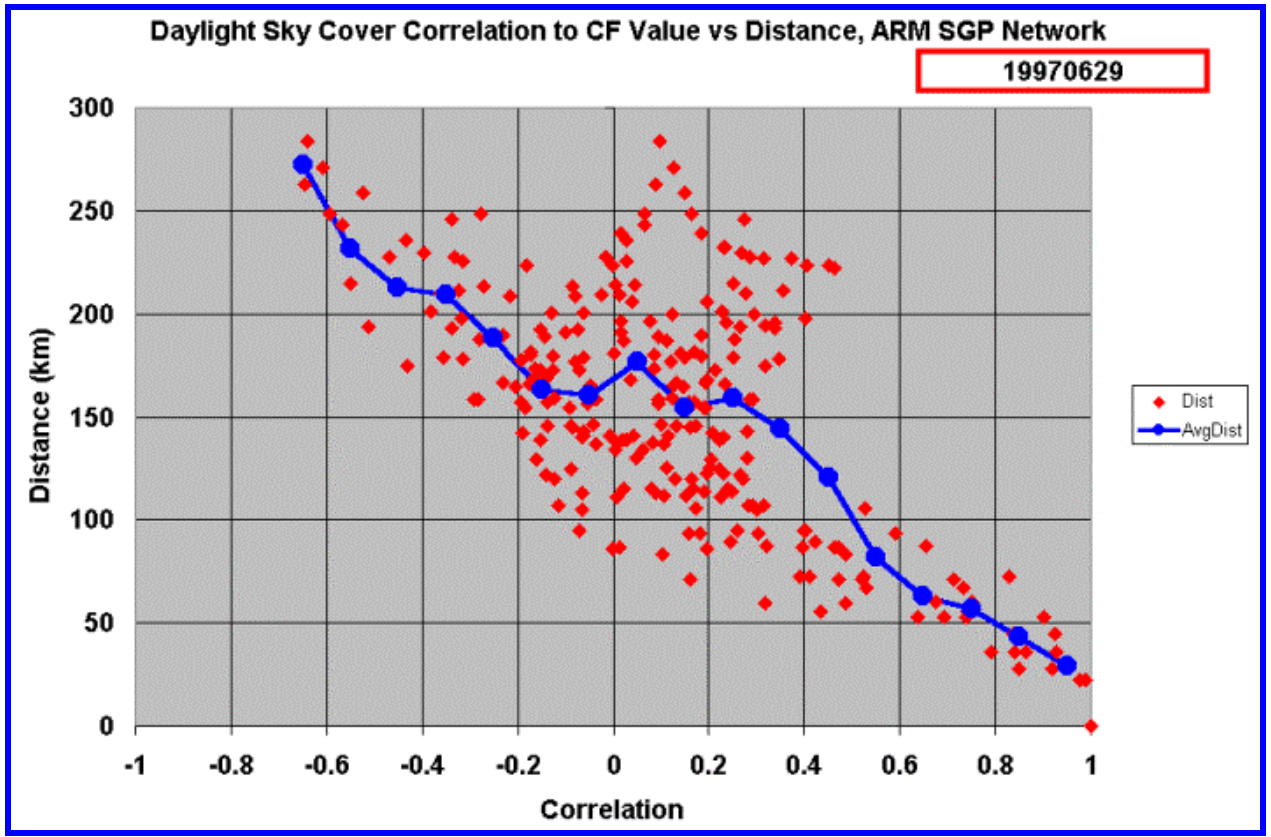

Figure 18. Same as Figure 16, but for 19970629.

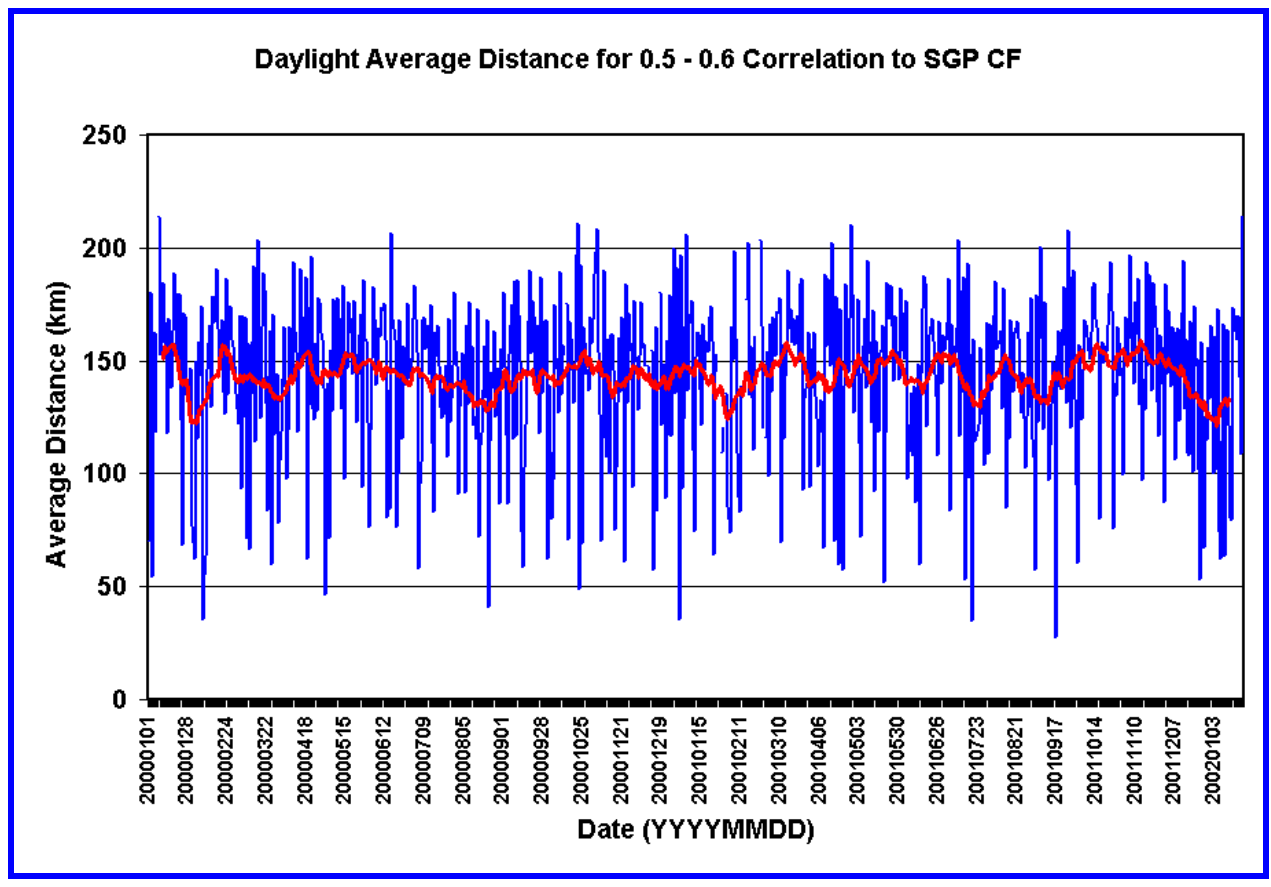

Figure 19. $0.5-0.6$ avg. correlation distance. 
Twelfth ARM Science Team Meeting Proceedings, St. Petersburg, Florida, April 8-12, 2002

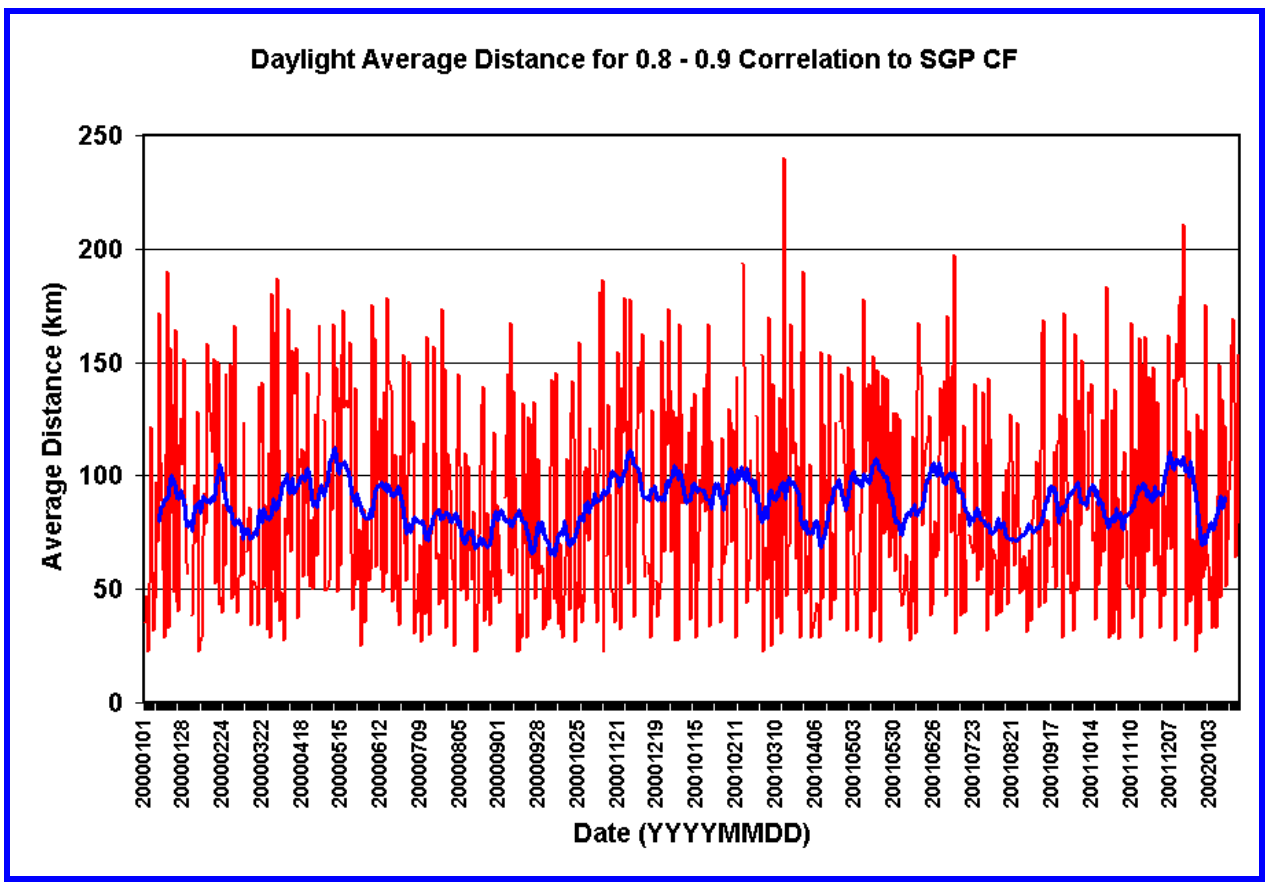

Figure 20. Same as Figure 19, but for 0.8-0.9.

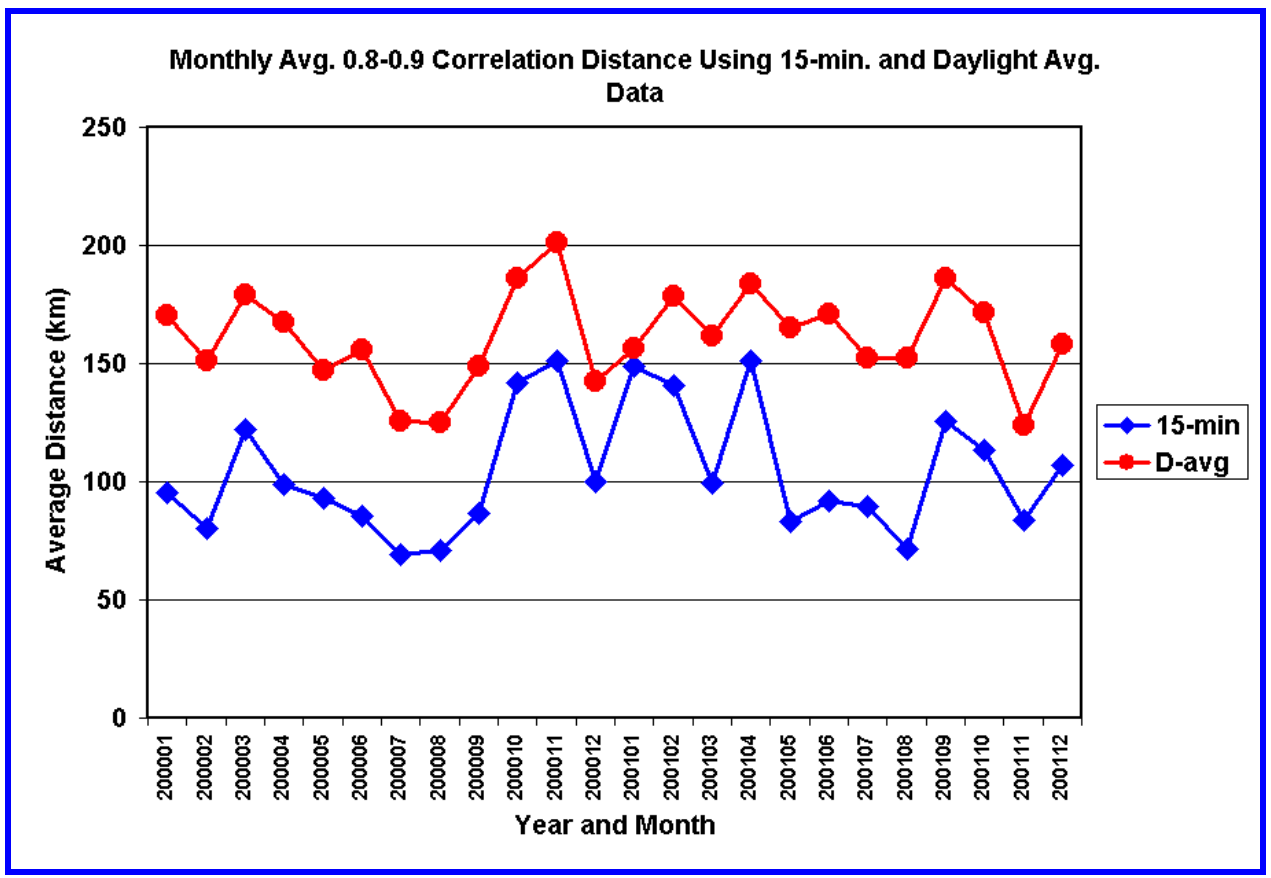

Figure 21. Monthly avg. 0.8-0.9 correlation distance. 
Figure 21 shows the average distance for $0.8-0.9$ correlation on a monthly basis. In this plot, the blue line represents the results generated using 15-minute data, while the red line represents the monthly results determined using daily averages. As expected, longer-time-averaged data gives better correlation results. The drawback is that longer time averages also preclude study of inherent temporal variability. One must choose a balance between the two depending on the needs of the particular research.

\section{Conclusions}

- As the spatial domain increases, variability increases, and the CF data is less representative of (correlated with) the larger area.

- The statistics of the GCM scale are not necessarily the same as those expected for a single surface site. As the domain size increases, frequency distributions of larger area averages tend more toward median values.

- As the period (length) of the statistical sampling time increases, the area representativeness of the CF data increases. And as the temporal averaging time increases, the area representativeness of the $\mathrm{CF}$ data increases, but information content on temporal variability decreases.

- A typical one month "IOP" period of CF values appears not to well represent the larger scale in mean, variability, or statistics. To date, most comparisons between measurements and models have used only data from the SGP CF. The results presented here show that this practice can and often does result in large uncertainties inherent in the comparison.

- The Surface Cloud Grid VAP allows us to quantitatively assess the representativeness of our CF data for comparison purposes. In addition, the data itself can be used to generate more representative statistics, particularly on sub-grid scale variability, for GCM comparisons.

\section{Corresponding Author}

Charles N. Long, chuck.long@pnl.gov, (509) 372-4917

\section{References}

Caracena, F., 1987: Analytic Approximation of Discrete Field Samples with Weighted Sums and the Gridless Computation of Field Derivatives. J. Appl. Meteor., 3:396-409.

Long, C. N., 2001: The Shortwave (SW) Clear-Sky Detection and Fitting Algorithm: Algorithm Operational Details and Explanations, Atmospheric Radiation Measurement Program Technical Report, ARM TR-004. Available URL: http:/www.arm.gov/docs/documents/tech_reports/index.html

Long, C. N., and T. P. Ackerman, 2000: Identification of Clear Skies from Broadband Pyranometer Measurements and Calculation of Downwelling Shortwave Cloud Effects. J. of Geophys. Research, 105, No. D12, 15,609-15,626. 
Long, C. N., T. P. Ackerman, J. J. DeLuisi, and J. Augustine, 1999: Estimation of Fractional Sky Cover from Broadband SW Radiometer Measurements. In Proceedings of the Tenth Atmospheric Radiation Measurement (ARM) Science Team Meeting, U.S. Department of Energy, Washington, D.C. 